\title{
Mendelian inheritance of streptomycin resistance in Nicotiana plumbaginifolia
}

\author{
Yen-Yu Kao, Chiu-Yueh Hung, Kin-Ying To, and Chi-Chang Chen \\ Department of Botany, National Taiwan University, Taipei, Taiwan, Republic of China \\ Received April 10, 1991/Revised version received July 30, 1991 - Communicated by J. M. Widholm
}

\section{ABSTRACT}

In a previous study two haploid streptomycin-resistant clones of Nicotiena plumbaginifolia were isolated. The chromosome number of one of these clones has now been doubled through leaf-midvein culture and the resultant diploids were characterized genetically. Our results show that streptomycin resistance in this clone is conditioned by a recessive nuclear gene. Haploid protoplasts of this streptomycin-resistant mutant were selected for chlorate resistance. All clones obtained from the selection were deficient in nitrate reductase activity in addition to resistance to streptomycin. Genetic analysis of progeny of one of these clones revealed that the genes for streptomycin resistance and for the apoenzyme of nitrate reductase are unlinked.

\section{INTRODUCTION}

Streptonycin is an aminoglycoside antibiotic which interferes with protein synthesis on bacterial-type ribosomes (Spotts and Stanier 1961, Davies et al. 1964). Mutants resistant to this antibiotic have been isolated from a wide variety of organisms including bacteria, algae, and higher plants. In Escherichia coli the resistance is caused by alterations in the 30 s subunit of the ribosome (Ozaki et al. 1969; Montandon et al. 1986; Melancon et al. 1988). In the green alga chlamydomonas reinhardtii both nuclear and cytoplasmic mutations have been shown to confer streptomycin resistance (Sager 1954; Lee and Jones 1973). The mechanism of the resistance caused by the nuclear mutations is not clear, while in the cytoplasmic mutants the resistance is due to alterations in the small subunit of the chloroplast ribosome (Harris et al. 1989; Liu et al. 1989). In higher plants there is only one case in which streptomycin resistance has been found to be conferred by a nuclear gene (Maliga 1981); in all other cases the resistance is conferred by a mutation in the chloroplast DNA ( Etzold et al. 1987; Galili et al. 1989; Fromm et al. 1989) and is inherited maternally (Maliga et al. 1975; Fluhr et al. 1985; To et al. 1989). In a previous study we (To et al. 1989) successfully isolated 20 streptomycin-resistant clones from protoplast cultures of haploid Nicotiana plumbaginifolia. Two of these clones were haploid and sterile, therefore, they could not be characterized genetically. In the present study, we doubled the chromosome number of one of these clones and studied the mode of inheritance of the resistance trait. Our results show that streptomycin resistance in this clone is conditioned by a recessive nuclear gene, sr. N. plumbaginifolia has been shown to be a modeI species in somatic cell genetics (Maliga 1984) but there is presently no genetic map. One area of our research with this species is the construction of genetic stocks with multiple markers for gene mapping. As a first step in achieving this goal, we selected chlorate-resistant clones from the streptomycin-resistant mutant and determined the linkage relationship between $\underline{s r}$ and the structural gene for the apoenzyme of nitrate reductase.

\section{MATERTALS AND METHODS}

Plant material. The haploid streptomycin-resistant clone, SROOO3, used in this study was isolated from protoplast cultures of haploid Nicotiana plumbagini-

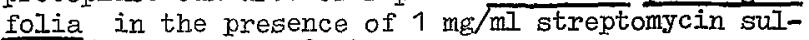
fate (To et al. 1989) and was propagated by culturing lateral buds in MS (Murashige and Skoog 1962) basal medium containing $1 \%$ sucrose and $0.8 \%$ agar. The chromosome number of this clone was doubled by culturing leaf midveins on MS basal medium supplemented with $0.1 \mathrm{mg} / 1$ 1-naphthaleneacetic acid (NAA) and $0.5 \mathrm{mg} / \mathrm{l}$ 6-benzylaminopurine (BAP).

Isolation of nitrate reductase-deficient clones. Nitrate reductase-deficient $\left(\mathrm{NR}^{-}\right)$colonies were selected from protoplast cultures of haploid SR0003 according to the scheme of Grafe et al. (1986). The method for protoplast isolation and culture have been described (Huang and Chen 1988). Colonies that were resistant to $40 \mathrm{mM} \mathrm{KClO} 3$ but were unable to utilize nitrate as the sole nitrogen source were transferred to AA medium (Müller and Grafe 1978) supplemented with $0.2 \mathrm{mg} / \mathrm{I}$ BAP for shoot induction. Shoot cuttings were embedded in hormone-free AA medium for root formation.

Chromosome number determination. Roots were collected from in vitro grown plants. They were ireated with $2 \mathrm{mM} 8$-hydroxyquinoline at $18^{\circ}$ to $20^{\circ} \mathrm{C}$ for $3 \mathrm{~h}$, fixed in ethanol-acetic acid. $(3: 1)$ overnight, stained by the Feulgen method, and treated with $1 \%$ pectinase for $1 \mathrm{~h}$. In the preparation of slides for chromosome counts, root tips were squashed in a drop of $4 \%$ acetic acid.

Enzyme assays. In vivo nitrate reductase (NR) activity was measured by the method of Jaworski (1971) using $200 \mathrm{mg}$ of leaf tissue. Xanthine dehydrogenase (XDH) activity was detected in crude extracts of leaf tissue after electrophoretic separation in polyacrylamide gels, as described by Mendel and 
Mïller (1976).

Genetic analysis. To study the inheritance of streptomycin resistance, diploid plants of $\$ R O 003$ were crossed reciprocally with the wild type. The $F_{1}$ plants were then self-fertilized and backcrossed to SRO003. Seeds from the crosses were germinated on MS basal medium containing $1 \mathrm{mg} / \mathrm{ml}$ streptomycin sulfate. Green seedlings were considered to be resistant while white ones were sensitive.

One $\mathrm{NR}^{-}$clone isolated from $\mathrm{SRO003}, \mathrm{SR}-\mathrm{NR}^{-}$, was used to study the linkage relationship between the genes for streptomycin resistance and for the axoenzyme of NR. Plants of this clone could not grow on their own roots, therefore, they were grafted onto plants of $\mathbb{N}$. tabacum cv. Wisconsin 38. Flowering grafts were crossed reciprocally to wild-type N. plumbaginifolia. The $\mathrm{F}_{1}$ plants were then backcrossed to SR-INR-8. Seeds from the crosses were germinated on BSR medium ( Gabard et al. 1987 ) containing $1 \mathrm{mg} / \mathrm{ml}$ streptomycin sulfate. Seedlings resistant to the antibiotic were subsequently transferred to $\mathrm{BNO}_{3}$ medium (Gabard et al. 1987) to test their ability to utilize nitrate as the sole nitrogen source, while those sensitive to the antibiotic were transferred first to streptomycin-free BSR medium for recovery, and then to $\mathrm{BNO}_{3}$ medium. Seedlings which could not grow on $\mathrm{BNO}_{3}$ medium were classified as $\mathrm{NR}^{-}$.

\section{RESULTS AND DISCUSSION}

The diploid plants obtained from leaf-midvein culture of haploid $\mathrm{SROOO3}$ were normal in appearance and were fertile. All seedlings grown from seeds obtained by self-fertilization of haploid SROOO3 were streptomycin resistant. $F_{1}$ hybrid plants between SR0003 and the wild type were all streptomycin sensitive regardIess the direction of the crosses. In the backcross and $F_{2}$ generations, streptomycin-sensitive and resistant plants segregated in a $1: 1$ and $3: 1$ ratio, respectively ( Table 1, Fig. 1). These data indicate that streptomycin resistance in SRO003 is governed by a recessive nuclear gene. We propose the symbol sr for this gene.

Table 1. Inheritance of streptomycin resistance in the mutant SROOO3

\begin{tabular}{|c|c|c|c|c|c|}
\hline Generation & $\frac{\text { No. } .5}{S^{a}}$ & $\frac{\text { Iings }}{\mathrm{R}}$ & $\begin{array}{l}\text { Test } \\
\text { ratio }\end{array}$ & $x^{2}$ & $\underline{P}$ \\
\hline \multicolumn{6}{|l|}{ P: } \\
\hline wt selfed & 657 & 0 & & & \\
\hline SRO003 selfed & 0 & 461 & & & \\
\hline \multicolumn{6}{|l|}{$F_{1}:$} \\
\hline wt $\times \mathrm{SRO003}$ & 217 & 0 & & & \\
\hline SR0003 $\mathrm{x}$ wt & 102 & 0 & & & \\
\hline \multicolumn{6}{|l|}{$\begin{array}{l}\mathrm{BC}_{1}: \\
(\mathrm{wt} \times \mathrm{SRO003)})\end{array}$} \\
\hline $\begin{array}{c}x \text { SRO003 } \\
\text { (SRO003 x wt) }\end{array}$ & 242 & 256 & $1: 1$ & 0.39 & $>.5$ \\
\hline $\mathrm{X} \mathrm{SROOO3}$ & 71 & 63 & $1: 1$ & 0.48 & $>.2$ \\
\hline \multicolumn{6}{|l|}{$\left.\mathrm{F}_{2}: \mathrm{SROO} 3\right)$} \\
\hline $\begin{array}{l}\text { selfed } \\
(\text { SR0003 } \times \text { wt) }\end{array}$ & 449 & 155 & $3: 1$ & 0.14 & $>.5$ \\
\hline selfed & 185 & 65 & $3: 1$ & 0.13 & $>.5$ \\
\hline
\end{tabular}

$a_{S}$ and $R$ represent sensitive and resistant, respectively, when seeds germinated on medium containing $1 \mathrm{mg} / \mathrm{mI}$ of streptomycin sulfate.

Streptomycin resistance conferred by a recessive, nuclear mutation has also been reported in $\mathrm{N}$. sylvestris (Maliga 1981) and C. reinhardtii (Sager 1954; Lee and Jones 1973). In the latter species, Harris

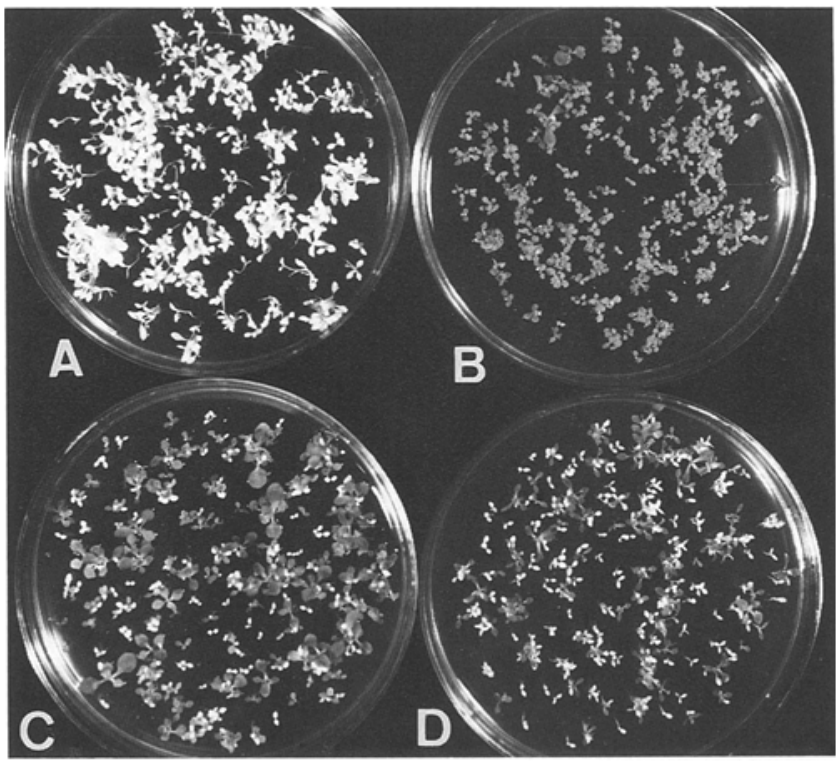

Fig. 1. Tests for streptomycin resistance where white seedlings show bleaching (susceptibility). Seeds from self-fertilization of wt $\mathbb{N}$. plumbaginifolia $(A)$, self-fertilization of mutant SROOO3 (B), backcross (wt $x$ SRO003) $\times$ SROOO3 (C), and self-fertilization of (wt $\times$ SRO003) (D) were germinated on medium containing $1 \mathrm{mg} / \mathrm{ml}$ of streptomycin sulfate.

et al. (1977) have shown that all the mutants analyzed by them are allelic, and Spiess and Arnold (1975) have found that the electrophoretic mobility of the chloroplast ribosomal proteins of one mutant is different from that of the wild type. These results seem to suggest that the nuclear streptomycin resistance locus in C. reinhardtii may code for a chloroplast ribosomal protein. In the case of SR0003, sr could be a structural gene for a chloroplast ribosomal protein, or a gene affecting the uptake of the antibiotic or its inactivation.

Leaf protoplasts of haploid SROOO3 were used for isolation of plants deficient in NR activity. From approximately $2 \times 10^{5}$ protoplast-derived cells plated in medium containing $40 \mathrm{mM} \mathrm{KClO} 3,21$ chlorate-resistant colonies were isolated. Subsequent tests showed that all. of these were unable to grow on medium with nitrate as the sole nitrogen source. Chlorateresistant colonies have also been isolated from protoplast cultures of haploid N. plumbaginifolia by other investigators. The frequency of chlorate-resistant colonies in this study is within the range of variation reported by Gabard et al. (1987) but is higher than those obtained by Marton et al. (1982) and Negrutiu et al. (1983). This difference is likely caused by the utilization of different selection procedures.

Nineteen out of 21 chlorate-resistant colonies produced plants upon transfer to the regeneration medium. The chromosome numbers of regenerated plants were present in a geometric series such as 10, 20 , and 40 (Table 2), suggesting that endomitosis and/or endoreduplication are mainly responsible for the changes.

Diploid plants of the chlorate-resistant clones were tested for NR activity. The results revealed that 13 clones had no detectable NR activity and 3 clones had pariial NR activity (Table 2). Tests for XDH activity showed that all clones except No. 10 had this enzyme activity (Table 2). Thus, among the $16 \mathrm{NR}^{-}$clones only one is presumably deficient in the molybdenum cofactor and was classified as the cnx type, while the remaining clones are likely defective 
Table 2. Chromosome numbers, nitrate reductase (NR) and xanthine dehydrogenase (XDH) activities of plants regenerated from the chlorate-resistant clones isolated from protoplast cultures of haploid SROOO3

\begin{tabular}{cccccc}
\hline $\begin{array}{c}\text { Chlorate- } \\
\text { resistant } \\
\text { clone }\end{array}$ & $\begin{array}{c}\text { No. plants with } \\
\text { the following } \\
\text { chromosome number }\end{array}$ & $\begin{array}{c}\text { NR } \\
\text { activity } \\
(\% \text { of wt })\end{array}$ & $\begin{array}{c}\text { XDH } \\
\text { acti- } \\
\text { vity }\end{array}$ \\
\cline { 2 - 6 } 10 & 20 & 40 & nd & nd \\
1 & 0 & 0 & 7 & nd & nd \\
3 & 0 & 0 & 5 & 0 & + \\
4 & 0 & 3 & 0 & 0 & + \\
5 & 0 & 4 & 0 & 0 & + \\
6 & 0 & 4 & 0 & 0 & + \\
7 & 5 & 2 & 0 & 0 & + \\
8 & 0 & 3 & 0 & 0 & + \\
9 & 4 & 2 & 0 & 0 & + \\
10 & 0 & 5 & 0 & 1.4 & + \\
11 & 0 & 3 & 0 & 6.0 & + \\
12 & 7 & 0 & 0 & $n d$ & + \\
13 & 0 & 5 & 0 & 0 & + \\
14 & 0 & 3 & 1 & 0 & + \\
15 & 0 & 7 & 0 & 0 & + \\
16 & 0 & 7 & 0 & 0 & + \\
17 & 1 & 2 & 1 & 0 & + \\
18 & 0 & 4 & 1 & 0 & + \\
20 & 0 & 7 & 0 & 9.7 & + \\
21 & 0 & 6 & 6 & 0 & + \\
\hline
\end{tabular}

$a_{\text {NR }}$ activity of wt: 812 nmoles $\mathrm{NO}_{2}{ }^{-} / \mathrm{g}$ fresh weight $\cdot 3 \mathrm{~h}$ nd: not determined

in the apoenzyme and were classified as the nia type. In contrast to this result, Gabard et al. (1987) found that approximately $40 \% \mathrm{NR}^{-}$ratants isolated from protoplast cultures of haploid N. plumbaginifolia were the cnx type. The recovery of a high proportion of cnx mutants has been attributed to an improvement in culture conditions which favor the regeneration of cnx callus (Gabard et al. 1987).

Table 3. Inheritance of streptomycin resistance and nitrate reductase deficiency in double mutant $S R-N^{-} 8$

\begin{tabular}{|c|c|c|c|c|c|}
\hline \multirow[b]{2}{*}{ Generation } & \multirow[b]{2}{*}{ Total } & \multicolumn{2}{|c|}{$\begin{array}{l}\text { Streptomycin } \\
\text { sensitive }\end{array}$} & \multicolumn{2}{|c|}{$\begin{array}{l}\text { Streptomycin } \\
\text { resistant }\end{array}$} \\
\hline & & $\mathrm{NR}^{+}$ & $\mathrm{IR}^{-}$ & $\mathrm{NR}^{+}$ & $\mathrm{NR}^{-}$ \\
\hline \multicolumn{6}{|l|}{ P: } \\
\hline wt selfed & 530 & 530 & 0 & 0 & 0 \\
\hline $\mathrm{SR}-\mathrm{NR}^{-} 8$ selfed & 312 & 0 & 0 & 0 & 312 \\
\hline $\begin{array}{l}F_{1}: \\
\text { wt } x \mathrm{SR}-\mathrm{NR}^{-} 8\end{array}$ & 556 & 556 & 0 & 0 & 0 \\
\hline $\begin{array}{l}\mathrm{SR}-\mathrm{NR}^{-8} \times \mathrm{wt} \\
\mathrm{BC}_{1}: \\
\left(\mathrm{wt} \times \mathrm{SR}-\mathrm{NR}^{-8}\right)\end{array}$ & 408 & 408 & 0 & 0 & 0 \\
\hline $\begin{array}{c}x \mathrm{SR}-\mathrm{NR}^{-} 8 \\
\left(\mathrm{SR}-\mathrm{NR}^{-} 8 \times \mathrm{wt}\right)\end{array}$ & 190 & 56 & 44 & 47 & 43 \\
\hline x $S R-N^{-} 8$ & 187 & 51 & 43 & 56 & 37 \\
\hline
\end{tabular}

The $\mathrm{NR}^{-}$clones isolated from SRO003 were designated as the $\mathrm{SR}-\mathrm{NR}^{-}$series. The only $\mathrm{cnx}$ clone in this study had partial NR activity, could grow in soil without special care, and was able to set seeds upon self-fertilization. Further characterization of this clone is necessary. Previous studies show that in N. plumbaginifolia there is only one structural gene for the apoenzyme of NR (Marton et al. 1982; Negrutui et al. 1983; Gabard et al. 1987). Clone $S R-N_{R}^{-8}$ was chosen to study the linkage relationship between the genes for streptomycin resis- tance and for the apoenzyme of NR. As show in Table 3, all seedlings from self-fertilization of $\mathrm{SR}-\mathrm{NR}^{-} 8$ were streptomycin resistant and NR". F1 plants between SR-NR-8 and the wild type were all streptomycin sensitive and $\mathrm{NR}^{+}$regardless the direction of the crosses. The ratio of streptomycin sensitive to resistant and of $\mathrm{NR}^{+}$to $\mathrm{NR}^{-}$fit the $1: 1$ ratio in backcrosses ( wt $\mathrm{x}$ SR-NR 8 ) $\mathrm{x} \mathrm{SR-NR} 8\left(x^{2}=0.526\right.$ and 1.346, respectively) and ( SR-NR $8 \times$ wt ) $x$ SR-NR 8 $\left(x^{2}=0.005\right.$ and 3.898 , respectively $)$. In both cases the four phenotypic classes fit the 1:1:1:1 ratio $\left(x^{2}=2.210\right.$ and 4.551 , respectively $)$. From these we conclude that $\underline{s r}$ and the structural gene for the apoenzyme of $\mathrm{NR}$ are unlinked.

The double mutant $\mathrm{SR}-\mathrm{NR}^{-} 8$ could be propagated in vitro in medium containing diammonium succinate and was fertile when grafted onto plants of $N$. tabacum $\mathrm{cv}$. Wisconsin 38. Thus, leaf protoplasts from the double mutant or its anther-derived haploids can be used for selection of other mutations such as herbicide resistance (Chaleff and Ray 1984) and valine resistance (Marion-Poll et al. 1988) until the desired multiple-marker stocks are obtained. The multiplemarker stocks are useful for gene mapping.

\section{ACKNOWLEDGEMENTS}

We are grateful to S. I. Tung for technical assistance. This study was supported by Grant No. NSC790211-B002-04 from the National Science Council, Republic of China.

\section{REFE'ERENCES}

Chaleff RS, Ray TB (1984) Science 223: 1148-1151 Davies J, Gilbert W, Gorini I (1964) Proc NatI Acad Sci USA 51: 883-890

Etzold T, Fritz CC, Schell J, Schreier PE (1987) FEBS Lett 219: $343-346$

Fluhr R, Aviv D, Galun E, Edelman M (1985) Proc NatI Acad Sci USA 82: 1485-1489

Fromm H, Galun E, Edelman M (1989) Plant Mol Biol 12: $499-505$

Gabard J, Marion-Poll A, Chérel I, Meyer C, Müller A, Caboche M (1987) Mol Gen Genet 209: 596-606

Galili S, Fromm H, Aviv D, Edelman M, Galun E (1989) Mol Gen Genet 218: 289-292

Grafe R, Marion-Poll A, Caboche M (1986) Theor Appl Genet 73: 299-304

Harris EH, Boynton JE, Giliham NW, Tingle CL, Fox SB (1977) MoI Gen Genet 155: 249-265

Harris EH, Burkhart BD, GiIIham NW, Boynton JE (1989) Genetics 123: 281-292

Huang HC, Chen CC (1988) J Hered 79: 28-32

Jaworski EG (1971) Biochem Biophys Res Comm 43:12741279

Lee RW, Jones RF (1973) Mol Gen Genet 121: 99-108

Liu XQ, Gillham NW, Boynton JE (1989) J Biol Chem 264: $16100-16108$

Maliga P (1981) Theor Appl Genet 60:1-3

Maliga P (1984) In: Vasil IK (ed) CeIl culture and somatic cell genetics of plants, Vol. 1. Academic Press, pp 552-562

Maliga P, Sz-Breznovits A, Márton L (1975) Nature 255: $401-402$

Marion-Poll A, Missonier C, Goujaud J, Caboche M (1988) Theor Appl Genet 75: 272-277

Márton L, Dung TM, Mendel RR, Maliga P (1982) MoI Gen Genet 182: 301-304

Melancon P, Lemieux C, Brakier-Gingras I (1988) Nucl Acids $\operatorname{Res} 16: 9631-9639$

Mendel RR, Müller AJ (1976) Biochem Physiol Pflanzen 170: $538-541$

Montandon PE, Wagner R, Stutz E (1986) EMBO J 5:37053708

Hül1er AJ, Grafe R (1978) Mol Gen Genet 161: 67-76

Murashige T, Skoog F (1962) Physiol Plant 15:473-497 
Negrutiu I, Dirks R, Jacobs M (1983) Theor Appl Genet 66: $341-347$

Ozaki M, Mizushima S, Nomura M (1969) Nature 222:333339

Sager R (1954) Proc Natl Acad Sci USA 40: 356-363
Spiess H, Arnold CG (1975) Ber Dtsch Bot Ges 88: 391398

Spotts CR, Stanier RI (1961) Nature 192: 633-637

To KY, Chen CC, Lai YK (1989) Theor Appl Genet 78:81- 